\title{
Initial Public-Health Emergency Response to SARS and COVID-19 Pandemics in Mainland China: A Retrospective Comparative Study
}

\author{
Huanhuan Zhu' \\ Qian Wang (D) \\ Tiantian Zhang ${ }^{2,3}$ \\ Xin Liu' \\ Ruiming Dai ${ }^{4}$ \\ Ping Wu' \\ Ge Bai ${ }^{\prime}$ \\ Ying Wang $\mathbb{D}^{\prime}$ \\ Ping Zhou' \\ Li Luo ${ }^{1,3,5}$ \\ 'School of Public Health, Fudan \\ University, Shanghai, 200032, People's \\ Republic of China; ${ }^{2}$ School of Social \\ Development and Public Policy, Fudan \\ University, Shanghai, 201203, People's \\ Republic of China; ${ }^{3}$ Key Laboratory of \\ Public Health Safety of the Ministry of \\ Education and Key Laboratory of Health \\ Technology Assessment of the Ministry of \\ Health, Fudan University, Shanghai, \\ 200032, People's Republic of China; \\ ${ }^{4}$ Department of Scientific Research, \\ Fudan University Shanghai Cancer \\ Center, Shanghai, 200032, People's \\ Republic of China; ${ }^{5}$ Shanghai Institute of \\ Infectious Disease and Biosecurity, \\ School of Public Health, Fudan University, \\ Shanghai, 200032, People's Republic of \\ China
}

Background: Severe acute respiratory syndrome (SARS) was reported first in China in 2003. The world is currently coping with coronavirus disease-2019 (COVID-19). We conducted a retrospective study to compare the initial public-health emergency response (PHER) to SARS and COVID-19 in mainland China.

Methods: A qualitative comparative study was conducted to compare the PHER timelines to SARS and COVID-19 by selecting six crucial time points. Besides, we explored the speed of spread, peak time and plateau period of SARS and COVID-19, respectively, by comparing the confirmed cases in the same time interval.

Results: The government of the People's Republic of China (PRC) accomplished the entire initial PHER to SARS in 127 days and for COVID-19 in 44 days. The speed of PHER for COVID-19 was 83 days faster. The peak time of SARS arose $\sim 80$ days later than that of COVID-19. Though the peak number of confirmed daily cases for COVID-19 was fivefold more than that of SARS, the onset of the stabilization period for COVID-19 was $>2$ months earlier than that of SARS.

Conclusion: Overall, the speed of the initial PHER to COVID-19 pandemic was faster than that for SARS. Compared with the speed of hospital reporting and government policymaking, the speed of pathogen identification improved the most. The COVID-19 pandemic curve entered a plateau period earlier than the SARS pandemic curve, which suggests that the pandemic was controlled more effectively because of a timely PHER. The PRC government should emphasize improving the ability of hospitals to restrain infectious diseases by enhancing the direct reporting system and cultivating crisis management to empower relevant individuals to make timely scientific decisions.

Keywords: severe acute respiratory syndrome, SARS, coronavirus disease-2019, COVID19 , infectious diseases, public health, emergency response

\section{Introduction}

Countries are facing increasingly complex public health $(\mathrm{PH})$ emergencies involving epidemics of infectious disease, natural disasters and human-made disasters. ${ }^{1,2}$ Such events are responsible for loss of life, disruption of the social fabric of society as well as unprecedented damage and cost. ${ }^{3}$

Severe acute respiratory syndrome (SARS) was first reported in 2003 in Guangdong, China, and gave rise to the first pandemic of the 21 st century. ${ }^{4}$ Coronavirus disease-2019 (COVID-19) emerged in Wuhan, China, in December 2019. COVID-19 has spread worldwide and elicited a severe crisis in PH worldwide. ${ }^{5,6}$ On 11 March 2020, the
Correspondence: Li Luo

Fudan University, I30 Dong'an Road, Xuhui District, Shanghai, 200032, People's Republic of China

Email liluo@fudan.edu.cn 
World Health Organization (WHO) declared COVID-19 a pandemic. $^{7}$ More than 220 million confirmed cases and $>4.5$ million deaths have been reported worldwide up to 7 September 2021.8 To fight against this pandemic, a preparedness plan worth US\$675 million was launched. ${ }^{9}$

SARS and COVID-19 are infectious diseases that share similar characteristics (Table 1), such as susceptibility regardless of age, probable development of severe respiratory diseases, and diseases caused by them are transmissible from person to person. ${ }^{10-13}$ The pathogen that causes COVID-19, severe acute respiratory syndrome-coronavirus 2 (SARSCoV-2), has a high rate of transmissibility, which increases the difficulty of prevention and control of the COVID-19 pandemic. $^{11-15}$ Therefore, an effective and timely public health emergency response (PHER) is crucial to reduce the adverse impact of emerging infectious diseases. ${ }^{16,17}$

Such a response is reliant mainly on the early surveillance and timely dissemination of information available in the early stage of an outbreak. ${ }^{18}$ In 2003, the SARS outbreak led to identification of deficiencies in surveillance and communication of risk in the $\mathrm{PH}$ system in China. A comprehensive reform from the People's Republic of China (PRC) government was activated to improve its $\mathrm{PH}$ emergency system. This was achieved by establishing a unified PH emergency management system through legislation, giving priorities to development of biotechnology industrialization and increasing investment in establishing a direct reporting system of infectious diseases. ${ }^{19}$ Within this perspective, the COVID-19 pandemic is not only a new challenge to the PRC government, it is also a test of the effectiveness of the new emergency response system.
Often, three key responses are analyzed to evaluate the efficiency of a PHER, ie, the time taken: (i) by the hospital to report an emerging infectious disease; (ii) to identify the pathogen; (iii) by the government to respond. ${ }^{20-22}$ However, few studies have focused on a comparison of the PHER between SARS and COVID-19.

We conducted a retrospective study to compare the initial PHER to SARS and COVID-19 in mainland China. We compared hospital reporting, pathogen identification and policymaking by the PRC government. We summarized the lessons learnt and proposed suggestions to improve the immediate response to future outbreaks in China.

\section{Methods}

\section{Selection of Time Points}

The emergency response of a government to a pandemic is chronological and, in general, involves "monitoring", "discovery", "investigation", "intervention", and "recovery" stages. $^{23,24}$ Therefore, we defined a series of measures and actions implemented as including monitoring, identifying, confirming and containing the pandemic before the exponential growth of the pandemic as the "initial PHER".

We selected six events as the critical "time nodes" from the total timeline of the initial PHER: the first identified case; hospital reporting to local authorities; pathogen isolation; completion of gene sequencing; publication of guidance for preventing and controlling the infectious disease by the national health authority; implementation of PHER policies by the national government. The entire timeline was divided into three phases (hospital reporting, pathogen identification and government policymaking). ${ }^{22}$ There

Table I Epidemiological Characteristics of SARS and COVID-19

\begin{tabular}{|l|c|c|}
\hline Characteristic & SARS & COVID-19 \\
\hline Susceptible population & People are generally susceptible to infection & People are generally susceptible to infection \\
\hline Clinical symptoms & Fever, weakness and cough, short of breath & Fever, cough, short of breath \\
\hline $\begin{array}{l}\text { Main route of } \\
\text { transmission }\end{array}$ & $\begin{array}{c}\text { Droplets, contact and short-range aerosol } \\
\text { transmission }\end{array}$ & $\begin{array}{c}\text { Droplets or fomites, contact and short-range aerosol } \\
\text { transmission }\end{array}$ \\
\hline $\begin{array}{l}\text { Average incubation } \\
\text { period/d }\end{array}$ & $5.21(4.00-7.00)$ & $4.75(3.0-7.2)$ \\
\hline $\begin{array}{l}\text { Basic reproduction } \\
\text { number }\end{array}$ & $1.7-1.9$ & $2.2-6.47$ \\
\hline Possible virus reservoirs & Bat & Bat \\
\hline
\end{tabular}


were reasons why we selected these time points to evaluate the reaction speed.

First, when the pandemic occurs, hospital staff are usually the first-responders and information-providers. ${ }^{22,24}$ Therefore, we chose the time of the first case identified and the case(s) reported by the hospital as the first two nodes to evaluate the sensitivity of hospital staff to new emerging infectious diseases. ${ }^{25}$ Second, technical identification of the pathogen is important. It can be used not only for clinical screening and the design of polymerase chain reaction (PCR) monitoring reagents, but is also crucial for follow-up treatment and epidemic prevention/control. ${ }^{21}$ Hence, we selected the time of pathogen isolation and acquisition of the genome sequence as the two nodes in pathogen-identification phase. Third, public awareness of the transmission dynamics of a new coronavirus is also important for preventing additional cases or poor health outcomes. $^{20,26}$ The earlier the public learn of the dynamics of disease transmission, the faster the national health department and national government react, and the more favorable is the work of pandemic prevention/control. ${ }^{27}$ Therefore, we chose the time points of publication of guidance for preventing and controlling the infectious disease by the national health authority, and the national government's implementation of centralized emergency policies, as the key nodes. ${ }^{25}$

\section{Comparisons}

Taking the time that the first case was identified as the baseline time point, we calculated the interval and accumulated days of each node and each phase. The results were applied to compare the speed of hospital reporting, pathogen identification and government policymaking between the SARS pandemic and COVID-19 pandemic.

The peak period and stable period are important signs of the progress of a pandemic because they show when the daily number of confirmed cases will begin to decline or stabilize. Hence, we compared the time of peak period and stable period of SARS and COVID-19, respectively, utilizing the number of daily confirmed cases.

\section{Data Sources}

We collected two types of data: the six key time nodes and cases data. Information about the six key time nodes for SARS was collected from the academic literature, ${ }^{28-31}$ WHO reports, ${ }^{32,33}$ information on the Chinese Center for Disease Control and Prevention (Chinese CDC) Internet website (IW), ${ }^{34}$ and announcements from the State Council Information Office of the PRC. ${ }^{35,36}$ Information about the six key time nodes for COVID-19 were collected from the academic literature, ${ }^{27}$ announcements from the Wuhan Municipal Health Commission, ${ }^{37}$ Hubei Government IW, ${ }^{38}$ Health Commission of Hubei Province, ${ }^{39}$ National Health Commission $^{40-42}$ and www.xinhuanet.com/. ${ }^{43}$

Data on SARS cases in mainland China were from academic literature, ${ }^{28,29}$ announcements from the Information Office of Guangdong Government and the Ministry of Health of China. ${ }^{44}$ Data on COVID-19 cases in mainland China were from the IW of the National Health Commission of the PRC. ${ }^{45}$

\section{Ethics}

After discussions with the Ethical Committee of the School of Public Health within Fudan University (Shanghai, China), our study was exempted from the need of ethical approval because the study protocol had neither an intervention nor a breach of privacy or anonymity. All data used in our study are publicly available on the related official IWs.

\section{Results}

The timeline of the initial PHER to the two pandemics are elaborated in Table 2. The pandemic curves for SARS and COVID-19 in combination with their initial PHER timelines are shown in Figures 1 and 2, respectively. The comparison results for the reaction speed in three phases are displayed in Figure 3. Details regarding the comparative analysis using the set of six key time nodes and three phases are shown below.

\section{Phase of Hospital Reporting SARS}

The first case was documented on 16 November 2002 at Foshan First People's Hospital (Foshan, China). ${ }^{28}$ As a result of a lack of awareness of SARS among health workers and the absence of a functional surveillance system for infectious diseases (the surveillance network employed reporting cards completed by hand and sent by mail or fax) at that time, ${ }^{46}$ the hospital could neither identify the potential risk nor report to the local CDC or authority in time. ${ }^{47,48}$ Heyuan People's Hospital received one patient (Mr. Huang) on 15 December 2002 (Figure 1, point 1). When atypical pneumonia of unknown cause began appearing among hospital staff, the hospital realized the seriousness of the matter and reported to the Health Department of Guangdong Province on 2 January 2003. ${ }^{28,29}$ Mr. Huang was the first identified case of SARS in China, so we set the starting point of the initial PHER to the SARS pandemic on 15 December 2002. 


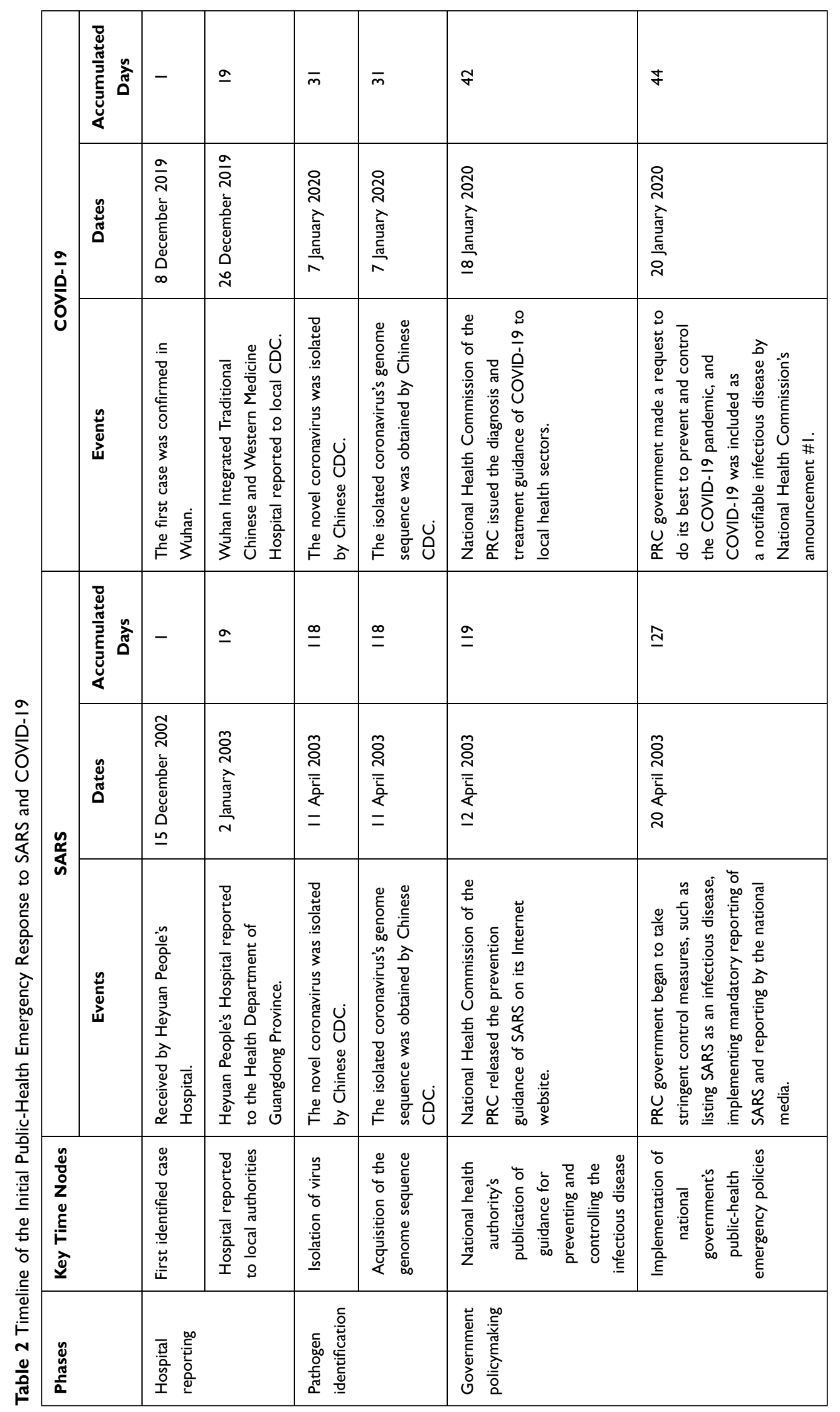


3500

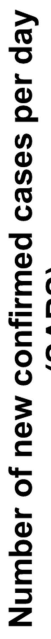

3000

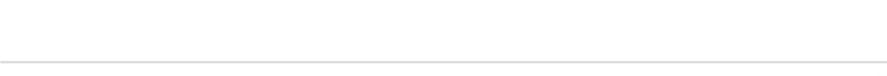

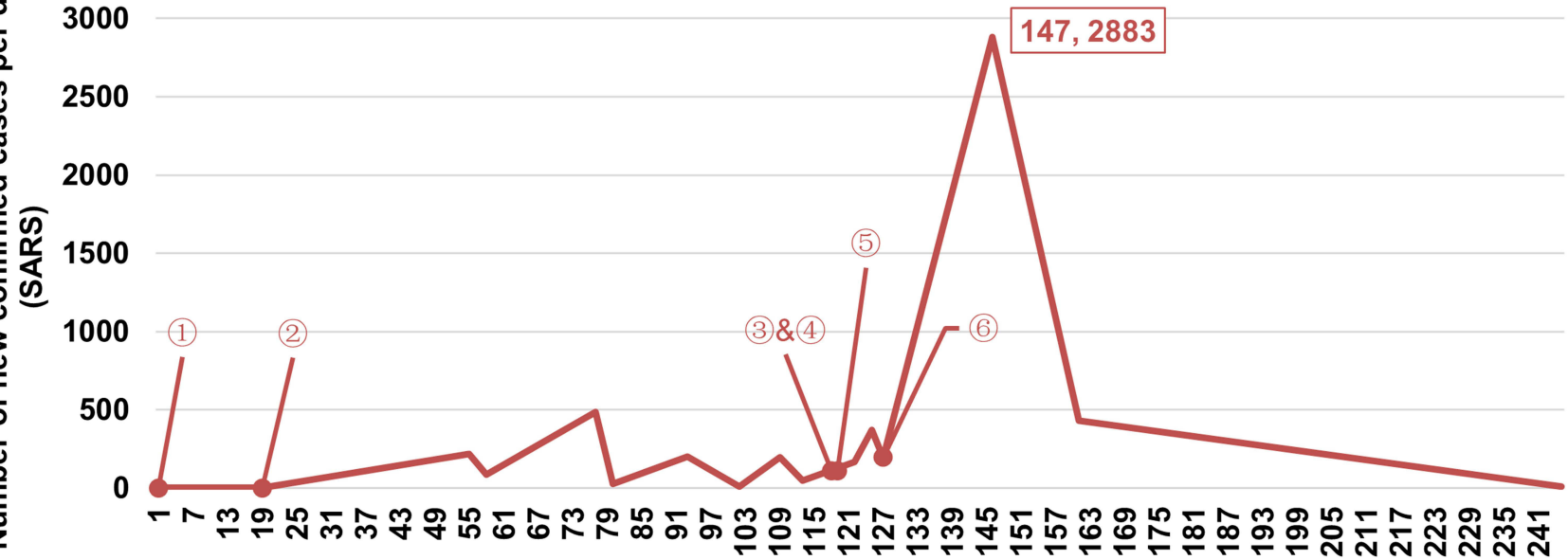

- Accumulated days

Figure I The Initial public-health emergency response (PHER) and progress of the SARS pandemic. Points (numbers in circles) reflect the accumulated days of key events and the number of new confirmed cases on that day. (I) First identified case (I5 December 2002). (2) Hospital reported to local authorities (2 January 2003). (3) Isolation of virus (II April 2003). (4) Acquisition of the sequence of the virus genome (II April 2003). (5) National health authority informed the public of the epidemiological characteristics and transmission dynamics of a very infectious disease (I2 April 2003). (6) Implementation of the PHER policies of the government (20 April 2003).

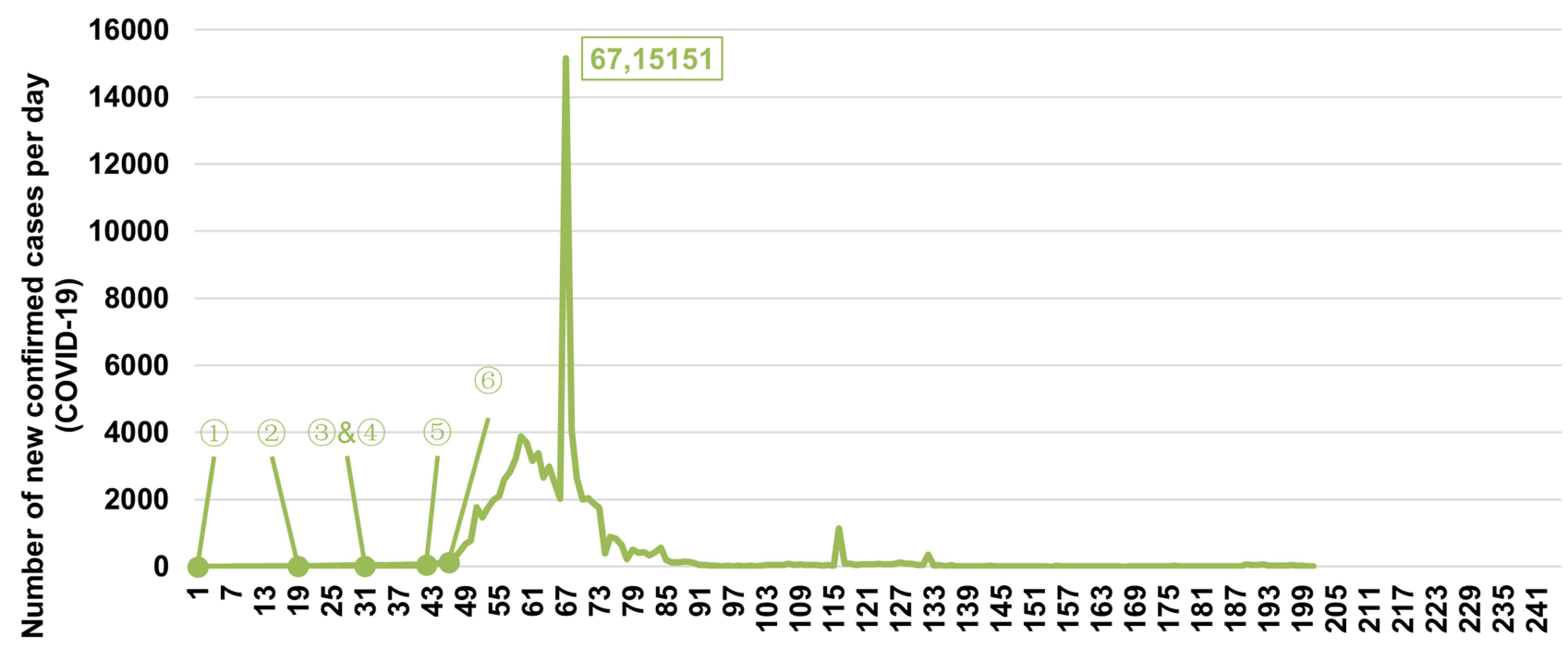

Accumulated days

Figure 2 The initial public-health emergency response (PHER) and progress of the COVID-19 pandemic. Points (numbers in circles) reflect the accumulated days of key events and the number of new confirmed cases on that day. (I) First identified case (8 December 2019). (2) Hospital reported to local authorities (26 December 2019$)$. (3) Isolation of virus (7 January 2020). (4) Acquisition of the genome sequence of the virus (7 January 2020). (5) National health authority informed the public of the epidemiological characteristics and transmission dynamics of a very infectious disease (I8 January 2020). (6) Implementation of the PHER policies (20 January 2020) of the national government.

\section{COVID-19}

On 11 January 2020, the Wuhan Municipal Health Commission stated through the media that the first COVID-19 case was identified on 8 December 2019
(Figure 2, point 1). ${ }^{37}$ The local CDC was informed by Doctor Zhang from Integrated Traditional Chinese and Western Medicine Hospital in Wuhan on 26 December 2019. ${ }^{38}$ 


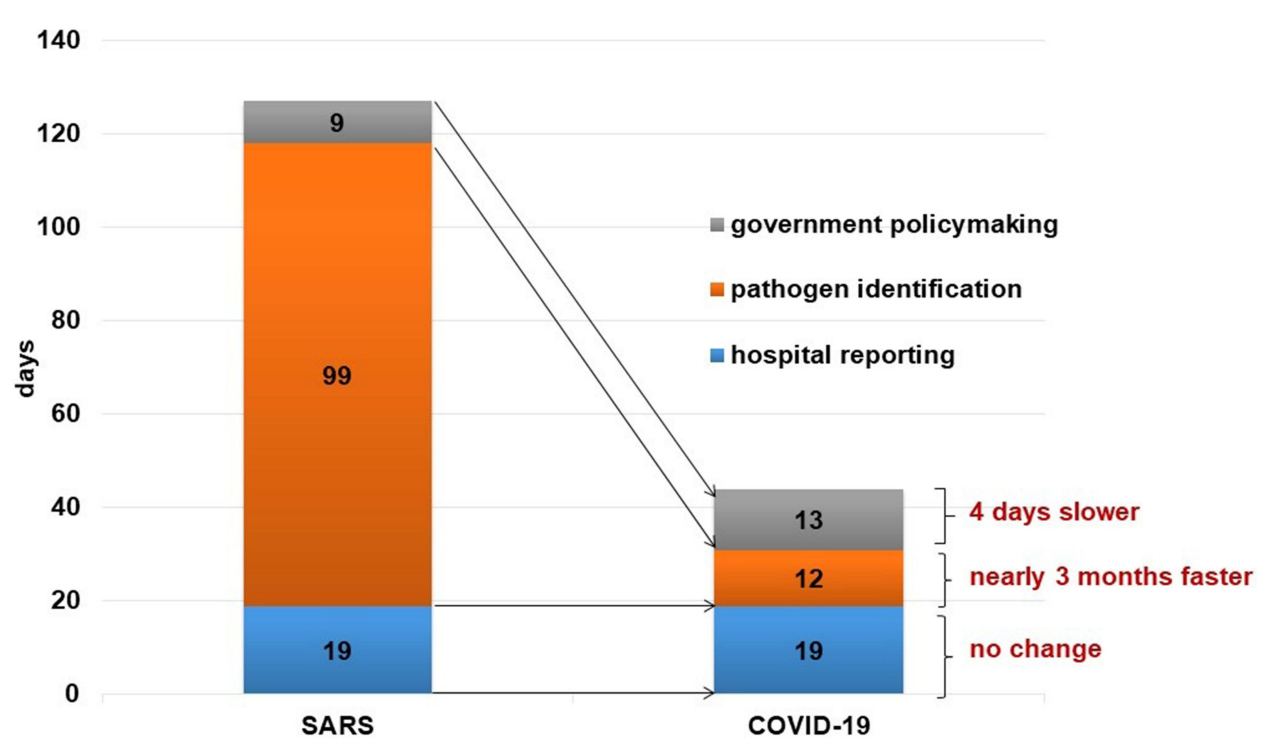

Figure 3 Speed of the public-health emergency response for SARS and COVID-19 in three phases.

\section{Reporting Duration}

The time that it took for the hospital to report was 19 days for SARS (Figure 1, point 2) and COVID-19 (Figure 2, point 2).

\section{Phase of Pathogen Identification SARS}

China had to tackle a public health emergency (PHE) caused by an unknown virus for the first time when SARS was documented. Science and research institutions in China judged that "the pathogen can be basically identified as chlamydia"; this misjudgment abrogated the chance to constrain the pandemic. ${ }^{49}$ With the collaboration of 13 laboratories from 10 countries and regions, the cause of SARS was confirmed. $^{32}$ On 22 March 2003, Peiris et al from Hong Kong University (Hong Kong, China) announced isolation of a new coronaviruses from patient samples. ${ }^{30,33} \mathrm{On}$ 12 April 2003, the Michael Smith Genome Science Center (Vancouver, Canada) sequenced the whole genome, and released the first genetic map of SARS-CoV. ${ }^{31}$ According to the information retained on the IW of the Chinese CDC, the Virus Research Institute isolated the virus and completed the genome sequence on 11 April 2003. ${ }^{34}$ We wished to focus on the PHER of China, so we adopted the time from the Chinese CDC due to the principle of comparability.

\section{COVID-19}

On 7 January 2020, a new type of coronavirus was identified from patient specimens. The genome sequence was obtained by the Chinese CDC on the same day. ${ }^{43}$ On 8 January 2020, the National Health
Administration confirmed that the virus was a novel coronavirus.

\section{Duration of Pathogen Identification}

The number of days for completion of pathogen identification starting from the first identified case were 118 days for SARS (Figure 1, point 3 and 4) and 31 days for COVID-19 (Figure 2, point 3 and 4).

\section{Phase of Government Policymaking SARS}

On 12 April 2003, the National Health Commission of the PRC publicized the prevention guidance for SARS on its IW. ${ }^{35}$ On 20 April 2003, the central government began to issue policies to curb the spread, such as listing SARS as a "tailored infectious disease" and implementing a mechanism for mandatory reporting. ${ }^{36}$

\section{COVID-19}

On 18 January 2020, the National Health Commission of the PRC sent guidance for the diagnosis and treatment of COVID-19 to local health sectors. ${ }^{41}$ On 20 January 2020, the PRC government made a request to prevent and control the COVID-19 pandemic, ${ }^{42}$ and COVID-19 was included as a notifiable infectious disease in announcement $\# 1$ by the National Health Commission. ${ }^{40}$ On 22 January 2020, the Hubei government launched the secondary emergency response plan (level II). ${ }^{39}$ 


\section{Duration of Government Policymaking}

The National Health Authority began to publicize guidance on the prevention and treatment 119 days after the first identified case for SARS (Figure 1, point 5), and 42 days for COVID-19 (Figure 2, point 5). Besides, the PRC government began to implement centralized emergency responses 127 days (Figure 1, point 6) after the first identified case of SARS, and 44 days after the first identified case of COVID-19 (Figure 2, point 6).

\section{Features of Pandemic Curves of SARS and COVID-I9 \\ SARS}

After the PRC government implemented centralized responses to SARS, the number of new daily confirmed cases increased sharply and reached a peak of 2883 on day-147 (10 May 2003) and then declined markedly (Figure 1). On day-163 (25 May 2003), the curve began to stabilize and obvious growth trends in the following three months were not observed.

\section{COVID-19}

After the PRC government implemented centralized reactions to COVID-19, the number of new daily confirmed cases of COVID-19 increased drastically and reached a peak of 15,151 on day-67 (12 February 2020) (Figure 2). On day-90 (mid-March 2020), the curve plateaued gradually. Some slight increasing trends during the plateau period were sporadic in subsequent months.

\section{Trends}

The peak of SARS pandemic occurred 147 days after the disease broke out. The peak of COVID-19 pandemic occurred 67 days after the disease broke out. The pandemic curve for SARS was relatively smoother than that of COVID-19. Both curves increased sharply and reached a peak $\sim 20$ days after the PRC government created centralized policies for an emergency response. Compared with SARS, the uptrend of COVID-19 was fiercer because the peak number of daily confirmed cases was fivefold more than that of SARS, but stable period for COVID-19 was $>2$ months earlier than that for SARS.

\section{Discussion}

An early response from local authorities is crucial to blunt the severity of PHE and save lives. ${ }^{16,17}$ This was one of the few studies to compare the strengths and weaknesses of the initial PHER between SARS and COVID-19. In this case-comparative study, we summarized the lessons learned and proposed suggestions to improve the immediate response to new outbreaks of infectious diseases.

The entire initial PHER to COVID-19 was much faster than that for SARS (44 days vs. 127 days). Among the three crucial phases, the speed of pathogen identification was improved most markedly. The time taken to identify the pathogen of COVID-19 was only 12 days, whereas for SARS it was $>3$ months. The rapidity of PHER to COVID-19 might have been a consequence of five lessons learned from the SARS outbreak in 2003. ${ }^{50}$

The first lesson was that the initial PHER became more standardized. The legal responsibilities of the PRC government, health administrative departments and medical institutions were stipulated and a systematic process was established through the Law of People's Republic of China on Prevention and Control of Infectious Diseases, and Regulation on Emergency Response to Public Health Emergencies after SARS. ${ }^{51,52}$ The second lesson was development of pathogen-identification technology. The PRC government prioritized development of biotechnology industrialization, especially in the areas of pathogen identification. The third lesson was that health authorities initiated various training programs in epidemiology at the national, provincial and municipality levels, and those programs might have strengthened the emergency preparedness and response capacity for healthcare workers. ${ }^{53}$ The fourth lesson was active collaboration with CDC in the USA. The capacity for communication on a PHE by the PRC government had improved tangibly, which could be attributed to the technical assistance from a program from the US CDC during 2006-2017 to enhance the riskcommunication capacity of the PRC. ${ }^{54}$ The fifth lesson learned was that social media (eg, Weibo ${ }^{\mathrm{TM}}$ ) and other technologies have evolved drastically in China, and provide prompt accesses to $\mathrm{PH}$ information. ${ }^{55}$

With respect to the stage of hospital reporting, SARS and COVID-19 consumed 19 days, which suggests the reporting speed has not improved (Figure 3). Therefore, as the first-responders and information-receivers, the knowledge of medical staff to infectious diseases must be strengthened periodically by education and training. ${ }^{56}$ The fact that the authorities in Wuhan punished the physicians who tried to warn about COVID-19 in combination with the long gap between the first case being identified and case(s) being reported suggest that some vulnerabilities remain in the direct reporting system. ${ }^{53}$ Thus, the 
PRC government must consider how to make the full use of the direct-reporting system.

The interval from completion of pathogen identification to policymaking by the PRC government was 13 days for COVID-19 and 9 days for SARS, so the speed of policymaking by the PRC government had not improved. The main cause was the lack of training concerning potential $\mathrm{PH}$ risks by provincial-level officials. Officials from Wuhan and Hubei underestimated the potential hazard of the emerging epidemic. Hence, the policies of the PRC government were not instituted as soon as they should have been. ${ }^{53}$ Risk-informed policymaking (especially during a pandemic) requires exceptional leadership that can prioritize rigorous approaches to producing high-quality data, and then putting a policy into action. ${ }^{57}$ We could explore new digital technologies to make full use of the information while the pandemic is developing, and cultivate crisis management for policymakers so that they can recognize the risk of the pandemic and make scientific decisions and policies in time. ${ }^{58}$

The peak of SARS came $\sim 80$ days later than that for COVID-19, and the pandemic curve for SARS was flatter than that for COVID-19 (Figures 1 and 2). In particular, the peak number of daily confirmed cases of COVID-19 was fivefold greater than that of SARS, which inferred that the spread of COVID-19 was fiercer than that of SARS. This phenomenon was due to three main reasons. The first reason was the stronger transmission of the virus. The basic reproductive number $\left(\mathrm{R}_{0}\right)$ of SARS-CoV-2 was 2.2 to 6.47 , which was higher than the $\mathrm{R}_{0}$ of SARS-CoV (1.71.9), so SARS-CoV-2 had a higher potential for sustained transmission in the community. The second reason was the flow of large populations. The Chinese Spring Festival in 2020 was earlier (the Lunar New Year Eve was 31 January in 2003 and the Lunar New Year Eve was 24 January in 2020), during which period $\sim 3$ billion holiday trips usually take place. In addition, Wuhan is one of the largest publictransportation hubs in China. Hence, flow of a huge population contributed the difficulty in controlling SARS-CoV -2 spread. The third reason was the completion of gene sequencing, which can also promote a sharp rise in the number of confirmed cases. Pathogen identification was beneficial for clinical screening and the design of PCRbased detection reagents.

The pandemic curves showed that peak arrived $\sim 20$ days after completion of policymaking by the PRC government, and then the number of new confirmed cases dropped quickly. On day-163 (25 May 2003), the pandemic curve for SARS began to stabilize and there were no obvious growth trends in the following 3 months. On day-90 (mid-March 2020), the pandemic curve for COVID-19 started to plateau gradually. Hence, the onset of the stabilization period for COVID-19 was $>2$ months earlier than that of SARS. To some extent, this phenomenon showed the effectiveness of the PRC government's strict measures to contain the COVID-19 pandemic: voluntary plus mandatory quarantine; forbidding mass gatherings; closure of education institutes or working places where infection had been identified; isolation of households, towns, or cities. 59

Indeed, in addition to this study, we also carried out two other studies at the same time, comparing the initial PHER to COVID-19 with H7N9 avian influenza in 2013 and influenza A (H1N1) in 2009, respectively. The former study found out the speed of the initial PHER for COVID19 was 5 days slower than that of H7N9 avian influenza, and both the speed of reporting an emerging infectious disease and policymaking of COVID-19 were slow. ${ }^{27}$ The latter study found out the speed of the initial PHER for COVID-19 was 18 days slower than that of H1N1 and the speed of hospital reporting, pathogen identification, and government policymaking of COVID-19 were all slower than those during H1N1 in the USA. ${ }^{60}$ Therefore, in combination with the results of this article, these findings confirmed the necessity of addressing the potential deficiencies in the current PHER again.

Our study had two main limitations. First, we used six time nodes to evaluate the PHER, but the PHER was also affected by the epidemiological characteristics, country demographics, age distribution, as well as testing, diagnostic and treatment capacities. However, we focused on comparing the speed of change of the PRC government and exploring the potential deficiencies in the current PHER. Second, due to a lack of transparency of data in 2003, some data and information about the SARS outbreak were integrated from academic articles, official IWs and other international reports, which might have introduced an information bias. Hence, we chose sources with high integrity and the results are credible.

\section{Conclusion}

In China, the speed of the initial PHER to COVID-19 was faster than that for SARS, which was affected mainly by the prior experiences and lessons learned from the SARS outbreak in 2003. Among the three phases (hospital reporting, pathogen identification and government policymaking), the 
efficiency of pathogen identification improved the most. However, deficiencies and limitations in early warning and policymaking by authorities remain. Three factors were the main contributors to the delay in hospital reporting: (i) frontline medical staff were not sufficiently knowledgeable of new emerging infectious diseases; (ii) the reporting system for an emerging infectious disease was not sufficiently effective; (iii) lack of training concerning potential PH risks by governmental officials.

The pandemic curve of COVID-19 was sharper, and the peak arrived earlier than those for the pandemic curve of SARS. These phenomena might have been affected by three factors: (i) SARS-CoV-2 was more infectious; (ii) flow of a larger population; (iii) more rapid pathogen identification. In addition, the pandemic curve for COVID-19 entered a plateau earlier than SARS epidemic curve, which demonstrated the effectiveness of the centralized response measures of the PRC government. An earlier centralized response to a pandemic increases the chance of controlling the pandemic. The PRC government should emphasize improving the ability of hospitals to restrain infectious diseases by enhancing the direct reporting system and cultivating crisis management to empower relevant individuals to make timely scientific decisions.

\section{Abbreviations}

SARS, severe acute respiratory syndrome; COVID-19, coronavirus disease-2019; PHER, public health emergency response; PRC, People's Republic of China; $\mathrm{PH}$, public health; PHE, public health emergency; WHO, World Health Organization; PCR, polymerase chain reaction; CDC, Center for Disease Control and Prevention; IW, Internet website.

\section{Acknowledgments}

We are grateful to all the participants for their compassion and collaboration in this study.

\section{Author Contributions}

All authors made a significant contribution to the work reported, whether that is in the conception, study design, execution, acquisition of data, analysis and interpretation, or in all these areas; took part in drafting, revising or critically reviewing the article; gave final approval of the version to be published; have agreed on the journal to which the article has been submitted; and agree to be accountable for all aspects of the work.

\section{Funding}

This study was supported by the National Natural Science Foundation of China (72174041) and Key Project of Philosophy and Social Science Research of the Ministry of Education of China (15JZD029).

\section{Disclosure}

The authors declare that they have no competing interests in this work.

\section{References}

1. Winkler AJ. Introduction to Public Health Preparedness for Disaster and Emergency Response. University of Texas School of Public Health; 2008.

2. National Academies of Sciences, Engineering, and Medicine; Health and Medicine Division; Board on Health Sciences Policy. Building a National Capability to Monitor and Assess Medical Countermeasure Use During a Public Health Emergency: Going Beyond the Last Mile: Proceedings of a Workshop. Washington (DC): National Academies Press (US); October 31, 2017. doi:10.17226/24912

3. Calonge N, Brown L, Downey A. Evidence-based practice for public health emergency preparedness and response: recommendations from a national academies of sciences, engineering, and medicine report. JAMA. 2020;324(7):629-630. doi:10.1001/jama.2020.12901

4. Li Z, Gao GF. Infectious disease trends in China since the SARS outbreak. Lancet Infect Dis. 2017;17(11):1113-1115. doi:10.1016/ S1473-3099(17)30579-0

5. Hui DS, Azhar EI, Madani TA, et al. The continuing 2019-nCoV epidemic threat of novel coronaviruses to global health - The latest 2019 novel coronavirus outbreak in Wuhan, China. Int J Infect Dis. 2020;91:264-266. doi:10.1016/j.ijid.2020.01.009

6. Lu H, Stratton CW, Tang YW. Outbreak of pneumonia of unknown etiology in Wuhan, China: the mystery and the miracle. J Med Virol. 2020;92(4):401-402. doi:10.1002/jmv.25678

7. World Health Organization. WHO director-general's opening remarks at the media briefing on COVID-19-11 March 2020; 2020. Available from: www.who.int/dg/speeches/detail/who-director-general-s-open ing-remarks-at-The-media-briefing-on-covid-19-11-march-2020. Accessed June 11, 2020.

8. World Health Organization. Weekly epidemiological update on COVID-19-7 September 2021; 2021. Available from: www.who.int/ publications/m/item/weekly-epidemiological-update-on-covid-197-september-2021. Accessed September 9, 2021.

9. World Health Organization. US\$675 million needed for new coronavirus preparedness and response global plan; 2020. Available from: www.who.int/news-room/detail/05-02-2020-us-675-million-neededfor-new-coronavirus-preparedness-and-response-global-plan. Accessed June 11, 2020.

10. Paules CI, Marston HD, Fauci AS. Coronavirus infections-more than just the common cold. JAMA. 2020;323(8):707-708. doi:10.1001/ jama.2020.0757

11. Petrosillo N, Viceconte G, Ergonul O, Ippolito G, Petersen E. COVID-19 SARS and MERS: are they closely related? Clin Microbiol Infect. 2020;26(6):729-734. doi:10.1016/j. cmi.2020.03.026

12. Singhal T. A review of Coronavirus Disease-2019 (COVID-19). Indian J Pediatr. 2020;87(4):281-286. doi:10.1007/s12098-02003263-6 
13. Lipsitch M, Cohen T, Cooper B, et al. Transmission dynamics and control of severe acute respiratory syndrome. Science. 2003;300 (5627):1966-1970. doi:10.1126/science.1086616

14. He W, Yi GY, Zhu Y. Estimation of the basic reproduction number, average incubation time, asymptomatic infection rate, and case fatality rate for COVID-19: meta-analysis and sensitivity analysis. $J \mathrm{Med}$ Virol. 2020;92(11):2543-2550. doi:10.1002/jmv.26041

15. Harapan H, Itoh N, Yufika A, et al. Coronavirus disease 2019 (COVID-19): a literature review. J Infect Public Health. 2020;13 (5):667-673. doi:10.1016/j.jiph.2020.03.019

16. Lee A, Morling J. COVID19: the need for public health in a time of emergency. Public Health. 2020;182:188-189. doi:10.1016/j. puhe.2020.03.027

17. Kapata N, Ihekweazu C, Ntoumi F, et al. Is Africa prepared for tackling the COVID-19 (SARS-CoV-2) epidemic. Lessons from past outbreaks, ongoing pan-African public health efforts, and implications for the future. Int J Infect Dis. 2020;93:233-236. doi:10.1016/ j.ijid.2020.02.049

18. Qiu W, Chu C, Hou X, et al. A comparison of China's risk communication in response to SARS and H7N9 using principles drawn from international practice. Disaster Med Public Health Prep. 2018;12 (5):587-598. doi:10.1017/dmp.2017.114

19. Wei P, Cai Z, Hua J, et al. Pains and gains from China's experiences with emerging epidemics: from SARS to H7N9. Biomed Res Int. 2016;2016:5717108. doi:10.1155/2016/5717108

20. Xiang NJ, Havers F, Chen $\mathrm{T}$, et al. Use of national pneumonia surveillance to describe influenza A(H7N9) virus epidemiology, China, 2004-2013. Emerg Infect Dis. 2013;19(11):1784-1790. doi:10.3201/eid1911.130865

21. Xiang NJ, Song Y, Wang Y, et al. Lessons from an active surveillance pilot to assess the pneumonia of unknown etiology surveillance system in China, 2016: the need to increase clinician participation in the detection and reporting of emerging respiratory infectious diseases. BMC Infect Dis. 2019;19(1):770. doi:10.1186/s12879-019-4345-0

22. Minisry of Health. Guideline for national surveillance, excluding and management on unknown etiology pneumonia; 2007. Available from: www.nhc.gov.cn/bgt/pw 10708/200708/4455f46a2f5e4908a8561 c079ecbcf0e.shtml. Accessed September 23, 2021.

23. Downey A, Brown L, Calonge N, editors. Evidence-Based Practice for Public Health Emergency Preparedness and Response. Washington (DC): National Academies Press (US); 14 July 2020. doi: $10.17226 / 25650$

24. The Central People's Government of the People's Republic of China. Law of the People's Republic of China on the prevention and treatment of infectious diseases (order of the president No. 17); 2005. Available from: www.gov.cn/banshi/2005-06/27/content_68756.htm. Accessed September 12, 2021.

25. AlKhaldi M, Kaloti R, Shella D, Al Basuoni A, Meghari H. Health system's response to the COVID-19 pandemic in conflict settings: policy reflections from Palestine. Glob Public Health. 2020;15 (8):1244-1256. doi:10.1080/17441692.2020.1781914

26. Knobler SL, Burroughs T, Mahmoud A, Lemon SM, editors. Ensuring an Infectious Disease Workforce: Education and Training Needs for the 21st Century: Workshop Summary. Washington (DC): National Academies Press (US); 2006. doi:10.17226/11563

27. Zhang TT, Wang Q, Wang Y, Bai G, Dai RM, Luo L. Early surveillance and public health emergency responses between novel Coronavirus Disease 2019 and avian influenza in China: a casecomparison study. Front Public Health. 2021;9:629295. doi:10.3389/fpubh.2021.629295

28. Feng D, de Vlas SJ, Fang LQ, et al. The SARS epidemic in mainland China: bringing together all epidemiological data. Trop Med Int Health. 2009;14:4-13. doi:10.1111/j.1365-3156.2008.02145.x

29. Yin J. SARS events. Chin J Dis Control Prevent. 2003;3:176-181.
30. Peiris JSM, Lai ST, Poon LLM, et al. Coronavirus as a possible cause of severe acute respiratory syndrome. Lancet. 2003;361 (9366):1319-1325. doi:10.1016/S0140-6736(03)13077-2

31. Marra MA, Jones SJM, Astell CR, et al. The genome sequence of the SARS-associated coronavirus. Science. 2003;300(5624):1399-1404. doi: $10.1126 /$ science. 1085953

32. World Health Organization. Coronavirus never before seen in humans is the cause of SARS; 2003. Available from: www.who.int/csr/sars/ archive/2003_04_16/en/. Accessed March 14, 2020.

33. World Health Organization. SARS virus isolated, new diagnostic test producing reliable results; 2003. Available from: www.who.int/csr/ sars/archive/2003_03_22/en/. Accessed March 14, 2020.

34. Chinese Center for Disease Control and Prevention. Events of Chinese Center for Disease Control and Prevention in 2003; 2006. Available from: www.chinacdc.cn/was5/web/detail?record=1\&pri marykeyvalue $=\%$ E6\%96\%87\%E6\%A1\%A3ID='8220'\&channelid= 133539. Accessed March 14, 2020.

35. National Health Commission of the People's Republic of China. The prevention guidance of SARS; 2003. Available from: www.nhc.gov. cn/wjw/zcjd/201304/2504e5d70a4d43ec80c79e332f6d2021.shtml. Accessed March 14, 2020.

36. The State Council Information Office of People's Republic of China. Gao Qiang's speech at the press conference of the State Council Information Office; 2003. Available from: www.scio.gov.cn/xwfbh/ xwbfbh/wqfbh/2003/0420/Document/327414/327414.htm. Accessed March 14, 2020.

37. Wuhan Municipal Health Commission. The latest interpretation report of the viral pneumonia whose cause was unknown by experts; 2020. Available from: www.wuhan.gov.cn/front/web/ showDetail/2020011109036. Accessed March 14, 2020.

38. Hubei Government. Decisions on rewarding Comrade Zhang Dingyu and Zhang Jixian for their great achievements; 2020. Available from: www.hubei.gov.cn/hbfb/bmdt/202002/t20200206_2020365.shtml. Accessed March 14, 2020.

39. Hubei Provincial General Office. Announcement of strengthening the prevention and control work of the novel coronavirus pneumonia epidemic; 2020; Available from: www.hubei.gov.cn/xxgk/gsgg/ 202001/t20200122_2013895.shtml. Accessed March 14, 2020.

40. National Health Commission of the People's Republlic of China. Announcement of the Health Commission of the People's Republic of China; 2020. Available from: www.nhc.gov.cn/xcs/zhengcwj/ 202001/44a3b8245e8049d2837a4f27529cd386.shtml. Accessed March 14, 2020.

41. National Health Commission of the People's Republic of China. prevention and control guidance of COVID-19 (Second Edition); 2020. Available from: www.nhc.gov.cn/jkj/s3577/202001/c67cfe29ec f1470e8c7fc47d3b751e88.shtml. Accessed April 18, 2021.

42. Central People's Government of the People's Republic of China. Premier Li Keqiang chaired the executive meeting of the State Council and further arranged the prevention and control plan for the novel coronavirus pneumonia epidemic; 2020. Available from: www.gov.cn/premier/2020-01/20/content_5471058.htm. Accessed March 14, 2020.

43. XINHUANET. Preliminary progress in pathogen identification of unexplained viral pneumonia in Wuhan; 2020. Available from: www.xinhuanet.com/politics/2020-01/09/c_1125438971.htm?baike. Accessed March 14, 2020.

44. Information Office of the Ministy of Health of China. Notification of SARS epidemic situation on August 16; 2003. Available from: www. nhc.gov.cn/wjw/zcjd/201304/a0d4975881e44d389195779773afaabc. shtml. Accessed September 12, 2021.

45. National Health Commission of the People's Republlic of China. Pandemic situation notification; 2021. Available from: www.nhc. gov.cn/xcs/yqtb/list_gzbd.shtml. Accessed September 12, 2021. 
46. Wang L, Wang Y, Jin S, et al. Emergence and control of infectious diseases in China. Lancet. 2008;372(9649):1598-1605. doi:10.1016/ S0140-6736(08)61365-3

47. Zhong N. Management and prevention of SARS in China. Philos Trans $R$ Soc Lond B Biol Sci. 2004;359(1447):1115-1116. doi:10.1098/ rstb.2004.1491

48. Wang Z. Investigation on Crisis Management of Public Health by Chinese Government-Cases of SARS and HFMD [Master's degree thesis]. Shanghai, China: School of International and Public Affairs, Shanghai Jiaotong University; 2009.

49. Enserink M. SARS in China. China's missed chance. Science. 2003;301(5631):294-296. doi:10.1126/science.301.5631.294

50. Yip WC, Hsiao WC, Chen W, Hu S, Ma J, Maynard A. Early appraisal of China's huge and complex health-care reforms. Lancet. 2012;379(9818):833-842. doi:10.1016/S0140-6736(11)61880-1

51. The National People's Congress of the People's Republic of China. Law on prevention and control of infectious diseases; 2004. Available from: www.npc.gov.cn/npc/c198/200408/0a3b6a64a23540a9a34 b75e3c52ec1a5.shtml. Accessed September 23, 2021.

52. The Central People's Government of the People's Republic of China Regulation on emergency response to public health emergencies; 2003. Available from: www.gov.cn/zhengce/content/2008-03/28/con tent_6399.htm. Accessed September 23, 2021.

53. Liu Y, Saltman RB. Policy lessons from early reactions to the COVID-19 virus in China. Am J Public Health. 2020;110(8):1145-1148. doi:10.2105/AJPH.2020.305732
54. Frost M, Li R, Moolenaar R, Mao Q, Xie R. Progress in public health risk communication in China: lessons learned from SARS to H7N9. BMC Public Health. 2019;19(Suppl 3):475. doi:10.1186/s12889-0196778-1

55. Anwar A, Malik M, Raees V, Anwar A. Role of mass media and public health communications in the COVID-19 pandemic. Cureus. 2020;12(9):e10453. doi:10.7759/cureus.10453

56. Li X, Huang J, Zhang H. An analysis of hospital preparedness capacity for public health emergency in four regions of China: Beijing, Shandong, Guangxi, and Hainan. BMC Public Health. 2008;8(1):319. doi:10.1186/1471-2458-8-319

57. Watson C, Mullen L. Risk-informed decision making: more critical today than ever before. Health Secur. 2020;18(3):153-154. doi:10.1089/hs.2020.0079

58. Deitchman S. Enhancing crisis leadership in public health emergencies. Disaster Med Public Health Prep. 2013;7(5):534-540. doi:10.1017/dmp.2013.81

59. Anderson RM, Heesterbeek H, Klinkenberg D, Hollingsworth TD. How will country-based mitigation measures influence the course of the COVID-19 epidemic? Lancet. 2020;395(10228):931-934. doi:10.1016/S0140-6736(20)30567-5

60. Wang Q, Zhang T, Zhu H, et al. Characteristics of and public health emergency responses to COVID-19 and H1N1 outbreaks: a case-comparison study. Int J Environ Res Public Health. 2020;17 (12). doi:10.3390/ijerph17124409
Risk Management and Healthcare Policy

\section{Publish your work in this journal}

Risk Management and Healthcare Policy is an international, peerreviewed, open access journal focusing on all aspects of public health, policy, and preventative measures to promote good health and improve morbidity and mortality in the population. The journal welcomes submitted papers covering original research, basic science, clinical \& epidemiological studies, reviews and evaluations,

\section{Dovepress}

guidelines, expert opinion and commentary, case reports and extended reports. The manuscript management system is completely online and includes a very quick and fair peer-review system, which is all easy to use. Visit http://www.dovepress.com/testimonials.php to read real quotes from published authors. 